\title{
Ancient Music, Modern Myth
}

The past is a foreign country; they do things differently there.

-L. P. HARTLEY, THE GO-BETWEEN

The past is another planet.

- NEIL DEgRASSE TYSON, COSMOS

In the fall of 2000, I was sitting in one of my classes at UCLA, eagerly awaiting an announced guest speaker. He was coming to teach us about traditional Persian music, one of Iran's great music traditions. I was excited because I already had some knowledge of Arabic and Turkish music, but at the time I knew much less about Persian music. Arabic and Turkish music had many similarities as well as a shared history, so it seemed that Persian music would relate to these other cultures of the Middle East in some way. But the concept of Persian music clearly referenced something different in my imagination. It was an image of great antiquity. Great Persian empires stood in Central and West Asia long before the Arab expansion or Turkic migrations overtook these empires, so surely Persian music could be older than music from these other large regional cultures. In my mind, the idea of Persian music certainly carried a unique sense of history and cultural prestige in comparison with these other large language groups of the region.

The guest lecturer arrived and proceeded to give us a history of Persian music that met with my expectations. He first established that Persia and Iran were one in the same. When people spoke of Persian music, they were in fact talking about Iranian music associated with the Persian language. He then acknowledged that scholars knew very little about music of ancient Persia, but some vague evidence of Persian music-making was still observable in bas reliefs and other artifacts found among the ruins of the Achaemenid Empire (700-330 BCE) and the Sassanian Empire (224-650 CE). He began teaching about the known history of Persian music from the same era of history when narrations of Arabic music history often begin: after the rise of Islam, starting around the ninth century CE. My assumptions were correct: the history he told did indeed portray Iranians as active partici- 
pants in a cosmopolitan music culture, first in the company of the Arabs and later in the company of Turkic and even Mongol peoples. There had basically been one general set of extensively documented musical principles that Iranians had shared with other language groups of the Middle East for many centuries, within a shared culture that paired Islam with a dynastic system of kingship. As the guest lecturer narrated this history, he highlighted key historical writings and sources on music in the Persian language, focusing on the very important role of Iranians in this extensive, sophisticated music culture.

Once he arrived at the sixteenth century, about halfway through the class, our guest stopped narrating this history and informed the class that Persian music went into decline for several centuries and afterward traditional Persian music became something completely different than anything he had just discussed. He then began to explain what traditional Persian music was now, speaking of a new system of music that emerged in the nineteenth century, distinct from the historical music principles he had just described. According to our guest's own knowledge of Persian music history, the music described in the first part of class was a wholly different phenomenon from traditional Persian music since the nineteenth century. It was a phenomenon of the modern era, while historic Persian music was something altogether different.

While the first part of his presentation had fit with my expectations of Persian music, the second part completely contradicted my assumptions about the historicity of Persian music. He was telling us that traditional Persian music did not come out of the mists of ancient Persian antiquity, nor did it come from a glorious renaissance of culture that came with the rise of medieval Islamic empire. Traditional Persian music came from the modern nation of Iran beginning in the nineteenth century, which marked a time and place of difficult turmoil. The images of a medieval ruler in his court, feasting surrounded by the sophisticated entertainment of his musicians evaporated. This was the music of a very complicated, modern place that had experienced two revolutions, authoritarian rule, and most recently an anti-imperial Shi'a Islamic regime. The historical narrative of ancient Persian music was clearly important to understanding Iranian music, but it did not explain key aspects of Iran's indigenous music in the modern era, which had a different structure as well as a different context.

I saw something very profound in this narrative and this change. The nineteenth century marked a pivotal moment in Europe's growing global influence and global interventions. The United States would eventually take over various aspects of Europe's global interventions, and much of Iran's modern history can be narrated according to which Western power asserted control over its national sovereignty, and how various constituencies within Iran attempted to reassert indigenous control against these different foreign interventions. In this context, it is not surprising that Iranians never wholly stopped playing music with indigenous roots. Though Western music had been (and, in many ways, still is) ubiquitous in 
Iran, they nevertheless maintain a unique tradition of Persian music that shows no obvious signs of Westernization.

This more recent music system functions within an indigenous framework that follows some basic tenets of all music in the Middle East. It has multiple melodic modes that use various pitches both within and beyond those used in Western scales. Playing music often involves various amounts of improvisation upon basic melodic phrases. There are rhythms played by drums that may accompany the melody. Performances consist of both unmetered improvisations by solo instruments and metered sections that are often composed. Metered compositions may be played by a soloist or a larger ensemble of instruments, and when the latter performs as a group, the metered melodies become heterophonic, with different instruments elaborating on the same melody in a slightly different way. The instruments common in the tradition include long-necked lutes, zithers, spiked fiddle, and endblowned flute, which all bear relation to musical instruments in other parts of the Middle East, Central Asia, and even South Asia. While a singer is not required to perform this music, it is desirable. When a singer is present, the instruments focus on accompanying the singer, but the basic process of working through unmetered improvisation and metered composition continues to prevail.

Traditional Persian music since the nineteenth century continues to share these types of musical features with other indigenous musics of its surrounding region. This is true if one compares traditional Persian music with historical practices, but it is also true if one compares it with contemporary indigenous music traditions across the cultures of the Middle East, Central Asia, and North Africa. In this sense, the modern manifestation of traditional Persian music is not an imported, alien musical phenomenon in its geographic and historical context. But the performance practice itself-how musicians decided to go about organizing their music to determine how they would actually learn it and play it-is both surprisingly specific and unlike the historic music taken as its ancient Persian antecedent.

In leaving the class and beginning my research, these specifics of organization and structure were central to my questions. At the heart of traditional Persian music's modern existence today is a melodic repertoire referred to as the radif (radif), organized into separate ordered sets of melodies referred to as dastgah (dastgāh). Both musicians and scholars remark on the unique nature of the radif, which has formed the basis of traditional Persian music's pedagogy and performance practice in the twentieth century. In historical documentation, it seems to have been formed around a distinct performance practice of the late nineteenth century, and the furthest back any family of musicians associated with that practice can be documented is the nineteenth century. The oldest any music scholar could responsibly declare it based on the historical evidence would be the late eighteenth century, and even this requires much speculation about what might have been. ${ }^{1}$ If one assumes that there really has been a continuous, multimillennia existence of Persian culture, 150 to 170 years of history barely registers as a signifi- 
cant space of time to practice a particular music tradition. But even in relation to the history of Persian-speaking people since the rise of Islam, the history of this particular music represents a very short legacy.

The melodic material of the radif ranges from short motifs to multisectional pieces, and it can be used as the basis of an instrumental or vocal improvisation or for composition. Though there were originally only seven dastgah within which this melodic material was ordered, sections of the original seven dastgah were subdivided in the twentieth century to create a total of eleven or twelve melodic complexes. Seven of the dastgah are still the largest of these melodic complexes, while four to five additional smaller complexes may be referred to as dastgah or avaz (avāz). In theory, each of these melodic complexes has a set of melodies that operate within a fairly distinct set of unique pitches. For this reason, both musicians and scholars tend to treat them as scales or modes. Yet it is the melodies of the radif themselves that define the traditional progression of unmetered improvisation and metered composition in performance. The melodies, referred to individually as gusheh ( $g \bar{u} s h e h$ ), determine which pitches will be used in the performance of a dastgah, and in what order specific sets of pitches can be used.

Historically, a performance of this radif-dastgah tradition consisted of musicians choosing a dastgah-or perhaps an avaz-dastgah-and creating a performance around the particular melodic material chosen. Musicians would improvise upon the gusheh of a dastgah in a fairly organized way, with some melodies being more improvised upon than others, even as most were unmetered. Additional metered compositions that are often not part of the radif appear at set times in the performance of a dastgah to supplement the mostly unmetered improvisation. These compositions are defined by how their rhythms are counted and their association with a given dastgah relates to how their pitch usage mirrors that of the gusheh in the dastgah.

While conducting my research, I wanted to know how and why this particular performance practice associated alternately with radif and dastgah developed as music particular to Iran in the modern era, and why a different approach to music-making was so important within educated courtly society in Persianspeaking lands for the six centuries previous. The older principles of music-making that held the narrative position of the radif-dastgah tradition's antecedent in the history of Iran's Persian music were quite different from radif or dastgah in significant ways. I came to refer to these older principles as the twelve-maqam system because they generally centered on twelve melodic modes, referred to alternately as maqam (maqām), shadd (shadd), or pardeh (pardeh). The twelve maqam were melodic modes that alternately broke down or combined in various ways to create additional modes. This distinct commitment to systematic, internal derivation and extraction of melodic modes was central to the twelve-maqam systems' conception. Within this closed system of melodic modes, any given modal entity needed to be matched with rhythmic cycles called usul ( $\bar{u} s \underline{u} l)$ to create an 
actual, functional melody. These melodies further related to an ever-changing set of compositional forms. Some forms were songs in Persian, Arabic, or Turkish, while others were instrumental pieces, but all had various configurations of primary and secondary melodies, recapitulations, and codas. In order to make music in the twelve-maqam system, musicians had to combine the use of a maqam or related melodic mode with an usul in the execution of these forms, which were structurally distinct from any of the gusheh or compositional forms of the radifdastgah tradition.

Both the radif-dastgah tradition and the twelve-maqam system arise somewhat suddenly in the historic record, and in each case this sudden rise correlates with a historical event. The radif-dastgah tradition emerged at the height of European colonization and intervention in the region, but also in a moment of monumental global transmutation in the history of humanity: the Middle East's full integration into the global economic system and the global system of nation-states. Yet the twelve-maqam system began to dominate educated musical discourse of the region in the midst of the Mongol invasion: the moment Genghis Khan's massive push for dominance over all of Asia overtook key parts of the Islamic world. These two different historical moments introduced different contingencies that changed the trajectory of history in West and Central Asia, even as the changes they affected caught people unawares. While modern Iranian musicians saw great continuity in the history of their national Persian music, I saw a historical record of great political and social disruption, often fostered by unforeseen circumstances. History writ large for the region could be told as an ongoing series of invasions, migrations, and other exogenous changes, involving various language groups over millennia. If such changes and disruptions were large enough, they could be key moments of cultural transformation that related to musical transformation.

\section{ANCIENT MUSIC, MODERN MYTH: RESEARCHING IDEOLOGIES IN THE MUSIC OF IRAN}

In the case of the radif-dastgah tradition, it was ethnographic researchers who were the first to address the extent to which it breaks with the norms established and maintained in the Persian-speaking world historically. Jean During suggested the radif-dastgah system did not directly descend from the twelve-maqam system, but rather seemed Azeri in origin. Indeed, the Qajar Dynasty-whose nineteenthcentury court in Tehran patronized the radif-dastgah tradition-was Turkic from Azeri territory. In addition to patronizing the radif-dastgah tradition at their seat of power in Tehran, they also patronized a similar music tradition sung in Azeri Turkish in their court in Tabriz. This court music of Tabriz became the basis for the music of Azeri mugham. ${ }^{2}$ Bruno Nettl further suggested that, though it was not Westernized per se, the radif-dastgah tradition still could represent changes that occurred in relation to the rise of Western musical hegemony in Iran dur- 
ing the late nineteenth and early twentieth centuries. He thought that the radif specifically could have been created out of a modern sense of Iranian nationalism. ${ }^{3}$ These contrasting hypotheses notwithstanding, both During and Nettl observed how different the radif-dastgah tradition was in relation to Persian music history and sought ways to explain why the modern phenomenon of traditional Persian music was so different from historical norms documented in Persian-language sources.

Nettl and During were just two of several foreign scholars studying music in Iran as it was in the late twentieth century and the primary focus on the ethnographic present at that time limited what researchers could conclude about musical change both during and before modern era. It did not, however, limit researchers' interest in expounding on the idea of an ancient Persian music history, nor did it prevent speculation about how the radif-dastgah tradition evolved out of the ancient ether of Persian music history. Though During's and Nettl's attempts to explain the conundrum of the radif-dastgah tradition's modern emergence are telling, they are also relatively unique within all ethnographic attempts to historicize the modern tradition. Ethnographic researchers have confidently dated the ultimate origins of Persian music to eras both before and after the rise of the twelve-maqam system. Thus, the ultimate origins of Persian music might be in pre-Islamic times (c. 550 BCE-650 CE), or the height of the 'Abbasid Caliphate (c. 750-950), or somewhat after the final fall of the 'Abbasid Caliphate in the thirteenth century, when Persian reemerged as a broadly-used lingua franca, and writings began outlining the basic tenants of the twelve-maqam system. ${ }^{4}$

When I first arrived in Iran to do research in 2003, I encountered Iranian musicologists arguing about the question of where the radif came from on fairly specific historical terms. Two scholars, Hooman Asadi and Mohsen Mohammadi, had begun a debate about the influence of the West that Nettl proposed, and the specific terms of musical change in the modern era. Iranian musicology more broadly was turning more attention to music from the sixteenth to the eighteenth century, an era that had been largely ignored in research conducted prior to the $1990 .^{5}$ Iranian musicologists took a period of history that had been considered a period of musical decline and demonstrated how it encompassed an extensive amount of musical activity. Their new discoveries have highlighted how there was continuous Persian music-making from the era of the twelve-maqam system into the modern era of dastgah and radif, and this has put more attention on the idea that the twelve-maqam could have gradually evolved into new approaches to musicmaking in the nineteenth century, which provided the basis for the radif-dastgah tradition as it came to exist in the twentieth century. As a result, the historical question of how Iranians evolved away from using the system of maqam into the system of dastgah and eventually radif has taken on a significance it did not have in the late twentieth century, and it is a question of paramount importance to Iranian scholars specifically. 
In reading, speaking with, and observing Iranian musicologists, I realized that my interests in Persian music history were quite distinct from theirs. They were seeking to write the one, true history of Persian music. This required one definitive explanation for how the twelve-maqam system turned into the modern system of traditional Persian music. For them, the gap between maqam and dastgah was a missing piece in a single culture's historic music puzzle. By contrast, I saw different cultures that dominated in different points in time, and distinct methods of musicmaking that related to these temporally distinct cultural spaces. I was researching at least two distinct cultural puzzles and looking for alignments between cultural change and changing conceptions of music.

My perspective was not one that could make much sense to my Iranian musicology counterparts. The music culture of radif I encountered in the twenty-first century was steeped in pre-radif music history, and previous ethnographers' testaments to the ancient nature of Persian music came directly from the conceptions of music history narrated by the Iranian musicians they worked with. A number of musicians in the radif tradition were musicologists, studying and editing editions of Persian music treatises written between the twelfth and nineteenth centuries, while also studying the Arabic treatises they believed to have been written by Iranians before the twelfth century. But one did not have to be so educated in specific historical information about music to make ancient historical perspective the basis of musical understanding. Some musicians I met knew far less about the specifics of these historical writings, but nevertheless referenced tropes of this premodern history in discussions, lessons, and lectures. One of the most common ways to do this was to reference commonalities in language and music jargon. On one hand, the general shared usage of Persian language was evidence of an ongoing, shared music culture. Yet both musicians and musicologists could also point to overlap in nomenclature: terms used to describe structures in the twelve-maqam system that also appear in the terminology of the radif-dastgah tradition.

This dependency on language analysis to create cultural commonality in music history fascinated me. To achieve a narrative of one specific shared cultural legacy of ancient Persian music, interpreting language over and above music was essential. The language provided opportunities for interpretation that music did not, yet the interpretation had to be very selective. Throughout the Middle East, there are overlapping pools of terminology that many types of music traditions from multiple language groups pull from in their application of music jargon. Persian terminology specifically is very common even in the music terminology of nonPersian speakers. The types of terms that get repurposed are often quite abstract and sometimes they do not have any demonstrable musical meaning in any particular tradition. When they do, the musical meaning could have multiple possible interpretations. When it is possible to compare actual music to its terminology, the fungible nature of language is apparent, even when everyone speaks Persian. For instance, in the radif-dastgah tradition, the term avaz has several different mean- 
ings. It is sometimes used to refer to the smaller dastgah, but it also refers to the vocal-based improvisatory section of a performance. It can also generally mean melody or song. In general modern Persian usage, it can mean any kind of sound, musical or not.

This case of music having a shaky relationship with language is not unique. Charles Seeger was the first to observe the general reality that language could not properly represent music, or be analyzed in place of analyzing music. ${ }^{6}$ But language remains a modern tool anyone can use to construct identities for music, identities that the music itself may or may not be able to validate. Focusing on general shared linguistic features of certain types of music in specific contexts has allowed ethnolinguistic identity to remain the central theme of Iranian music history. Musicians can talk about what have become the great names of Iranian music history, mixing premodern treatises by writers like al-Farabi (d.c. 950) and 'abd al-Qader al-Maraghi (d.c. 1435) with names of the earliest known practitioners of radif, such as Mirza 'Abdullah (c. 1843-1918) and Husayn Qoli (d. c. 1915). They understand that the music system used by Mirza 'Abdullah and Husayn Qoli was not discussed by premodern treatise writers. But they did share some music terminology and they probably also shared some semblance of a mother tongue. This overlap in language provides a rhetorical bridge to narrate Iran's singular Persian music history, even when that narrative relies on cultural commonality between diverse historical realities and their divergent concepts of music. Major differences in music's conception, structure, and value at different points in time could not represent any significant change in the cultural order, as long as the ethnolinguistic bond of the language could be found in either general or specific terms. In this context, no one has been waiting to understand the specific way the maqam could have evolved into the dastgah before declaring Iran's claim to a long history of Persian music valid. No one needs to know how the transformation occurred exactly to know that these two systems have to be connected and defined by a single shared culture.

My idea of different music existing at different points in time because of distinctions in culture over time was not simply foreign in the realm of Persian music research because it was somehow foreign to Iranian sensibilities. In the case of Persian music, the narrative of a single, ethnolinguistic, national music history has been underpinned by Western scholarship, specifically some of the earliest research done on music of the Middle East in Europe under the nineteenthcentury rubric of Oriental studies. By the 1930s, some practitioners of the radifdastgah tradition had received education in Europe and knew that Europeans had researched ancient music of the Arabic- and Persian-speaking world, and that this research had revealed a distinct, noteworthy history that Europeans saw as being Persian in nature. Information on the work of Oriental musicologists such as Raphael Georg Kiesewetter (1773-1850), and Jan Pieter Nicolaas Land (1834-1897) appears in some of the early writings about the radif-dastgah system. The earliest 
attempts of radif-dastgah musicians to trace a single Persian music history focused on making a connection between the ancient twelve-maqam system, which Orientalists praised, and their own radif-dastgah tradition. ${ }^{7}$

Though Orientalist scholars had a big impact on how the history of Persian music would ultimately be told, Iranians were always providing their own interpretations of how Persian culture related to Iran's history of music. In 1942 the Iranian Journal Rūzgar-i Naw published two articles attributed to the prolific Orientalist musicologist Henry George Farmer (1888-1966). One was titled “The Great Sciences of Iran in the Art of Music" ("Ulamā'-i bozorg-i İān dar fann-i mūsīqī”) and the other "The Impact and Influence of Iran on the Construction of Instruments" (“Ta’tīr va nufūz -i İān dar tạb'īyat-i alāt-i mūsīqī”). ${ }^{8}$ These articles were indigenous explanations of information from Farmer's chapter in Arthur Upham Pope's multivolume magnum opus A Survey of Persian Art from Prehistoric Times to the Present, published in 1938. Ironically, Farmer depended heavily on Arabic sources and French translations of Persian texts to write this chapter and mostly spoke of cross influences between Persians and Arabs. Conversely, the Persian interpretations of his work said less about the Arabs, and much more about Iran, taking Farmer's article as validation of Iran's historic musical legacy. Yet publishing the reinterpretation of Farmer's work in Persian under his name validated the veracity and importance of the information, even more than published research under a Persian name.

This borrowing and reinterpreting of Orientalist musicology research on music of the Middle East were thus ongoing and pervasive before ethnographic research began on the radif-dastgah tradition later in the twentieth century. Europeans were telling Iranians they had a great history of Persian music worth preserving. This may not have been the dominant message coming from Europe, but it was a message indigenous peoples of the Middle East heard from Europe and it did not fall on deaf ears. Henry George Farmer was at the 1932 Congress of Arab Music of in Egypt, where he was one of several European voices making this argument to Arabs in support of their unique music heritage against the pervasive growing influence of Western music. The comparative musicologists from Europe further asserted this perspective on the broader basis that Arabs had different music from Europe because of their distinct racial traits. Many Arab voices at this conference favored adapting to a more Western music aesthetic, but key Europeans voices were there to argue in favor of the indigenous music. ${ }^{9}$ Farmer echoes these sentiments in his chapter on Persian music from 1938. He begins with the statement "In spite of the many alien influences traceable in Persian culture over a period of several millennia, Babylonian, Assyrian, Greek, Aramaean, Indian, and Arabian, there is perhaps something sui generis in Persian music." ${ }^{\circ} \mathrm{He}$ ends the chapter by complaining that the import of Western-style military music to Tehran was "Occidentalizing the Persian musical ear, to the detriment of the native art." ${ }_{11}$ 
While Orientalist research and comparative musicology have proved to be underpinned by problematic assumptions and issues of racial bias, not all music scholars or musicians of "the East" want to remove themselves from their joint legacy. In Iran, the musicians and the musicologists often value Orientalism's focus on the great "otherness" of Eastern music history, which they understand to be mostly Iranian music history. From the perspective of Iranian musical intellectuals I met, it was clear that Orientalists found Iran's long-lost music of ancient times and demonstrated how Iran's Eastern music had a great musical sophistication and great history that are both distinct yet comparable to Europe. Iran having its own distinguished music culture and distinct music history vis-à-vis the West is part of larger nativist discourses against the domination of Western culture in Iran, of which there are many.

The priorities of Orientalist musicology and comparative musicologists also involved many nineteenth-century ideas that still hold sway in American higher education. Orientalist musicology focused on history and the historic writings in Arabic and Persian that referenced ancient Greek philosophy, a central aspect of academic learning in the West even today. Medieval writing on music first appeared in Arabic between the ninth and thirteenth centuries CE, and then continued in Persian starting sometime around the thirteenth century. Orientalist musicology initially took an interest in historic Arab and Persian music because of its ties to ancient Greek music, which tied Oriental music history to Occidental music history. Yet the distinct contributions of Arabs and Persians based on their unique histories and racial distinctions eventually became important, even as such racial distinctions were also the basis for the analysis of music in comparative musicology. ${ }^{12}$

In focusing on the individual writings of a handful of authors, Orientalists also established a certain degree of Great Man Theory in their musicology, with each medieval author representing a musical genius, from which unique aspects of genius among the races of the Middle East could be observed. Europe had Bach, Brahms, Beethoven, within an endless list of composers and theorists, while the ancient Middle East mostly had great music theorists like al-Kindi (c. 801-866), al-Farabi, Ibn Sina (980-1037), Safi al-Din Urmawi (d. 1294), Qutb al-Din Shirazi (c. 1300), and 'abd al-Qader al-Maraghi. On this basis, Kiesewetter famously proclaimed Safi al-Din Urmawi to be the "Zarlino of the Orient," with one genius of the East mirroring another genius in the West. ${ }^{13}$ Among the Arabs and the Persians, each genius revealed some aspect of the race's musical and cultural truth. Orientalist musicological writings sought to understand a single, verifiable, correct truth of music history among the races of the region via the study of individual geniuses.

The lingering legacy of Oriental studies in scholarship on music of the Middle East tends to present some functionalist limitations on what music and musical change could possibly mean. If Iran's Persian identity is sui generis, then tra- 
ditional Persian music will always be a mere reflection of Iran's Persian culture no matter how much music and society change. In moments of massive social upheaval, music can only serve to maintain the complex whole of Persian culture. While other music traditions of the world demonstrate the agency of music to engage in social protest and the inversion of social norms, or even to foster unique subcultures of their own, traditional Persian music largely continues to simply represent the continuity of a predetermined cultural order.

It is within this functionalist/positivist framework of understanding-and Iran's knowledge of it - that most of the modern historiography of Persian music currently resides. Yet this is not purely a conundrum of Persian music or Iran. In many of the nations around Iran, musicians and researchers often want to know what music of the past was really like, and how much historic indigenous traditions have in common with contemporary traditions. These avenues of inquiry often occur via set ethnolinguistic categories. Thus cultural categories like Persian, Arab, Turkish (or Azeri, or Kurdish, or Uzbek, or Afghan) can stand as a priori, while researchers focus on analyzing the music itself and inserting it into a predetermined cultural category of historical development. In this context, musical analysis proceeds largely from the presumption that modern ethnolinguistic identities have a perennial existence in the known history of music in the Middle East, no matter how awkward or incomplete the resulting historical narrative might be.

The focus on reconstructing individual ethnolinguistic music histories has allowed scholars to focus their analysis on what music of the past might have looked like, sometimes in great detail. Conversely the meaning of it all remains open to interpretation and standing disagreements on music's meaning seem unending. Today, Iranians, Arabs, Turks, Afghans, Uzbeks, and Tajiks could argue ad infinitum about which group gets to claim the historic legacy of great music thinkers like al-Farabi, Safi al-Din Urmawi, and Maraghi. These arguments stem from the ambiguity of these figures' historical context in relation to current ethnolinguistic realities. ${ }^{14}$ They physically and intellectually moved between language groups, with no comment about where they were born or what language they spoke from birth. Instead, they focused their lives on the urban spaces where patrons of their work could be found, and they wrote in whatever the lingua franca was in their time and place. Thus, while the twelve-maqam system had a general region of practice, it was not defined by any one language group, race, or nation.

By contrast, the modern tradition of Persian music is very defined by a national ethnolinguistic identity. The radif-dastgah tradition belongs to Iran and only Iran, referred to by musicians and scholars using such labels as traditional Iranian

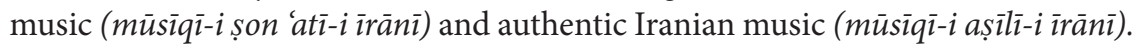
Practitioners of the radif-dastgah tradition might leave Iran and live almost anywhere on Earth, but this music tradition would still be Iranian. Before this tradition existed, historical documentation discussing music did not use Iran as a geo- 
graphic concept that delineated where on the map music practices would start or stop. Whether it was purely theoretical music ( $m \bar{u} s \bar{i} q \bar{\imath})$, sophisticated urban music practices (ghinna'), or basic melody and rhythm (lahn and $\bar{q} q \bar{a}$ ), the adjective Iranian (ìrānī) did not relate to music. People of the past were not blind to differences in different peoples, languages, and locations. Indeed, musicians tended to occupy predominantly cosmopolitan spaces where music-making must account for such differences. It was not enough to make music for Persian-speaking people ('ajam). Music had to speak across languages.

In continuing to read music treatises about the twelve-maqam system written in Persian and Arabic as far back as the thirteenth century, the differences I saw between the radif-dastgah tradition and the twelve-maqam system became more striking. The twelve-maqam system clearly shares features with music traditions of the Middle East and Central Asia cross-culturally, as does the radif-dastgah tradition. ${ }^{15}$ Yet the rise of a traditional Persian music based on the organizational principles of dastgah and radif in the nineteenth century pivoted away from the twelve-maqam system's organizational principles in significant ways. In his expansive analysis of modal concepts in the Middle East and South Asia musicologist Harold Powers analyzed Turkish and Arabic modal concepts together, but had to analyze modal concepts in the radif-dastgah tradition separately. ${ }^{16}$ The historic twelve-maqam system had more in common with the latter than the former, in terms of both structure and execution.

Even beyond basic structural features, however, the twelve-maqam system was epistemologically different from the radif-dastgah tradition. Structural features and music-making processes were different, and these differing structural features had different meanings and goals even as they necessitated different music-making processes in very different contexts. These two music systems were from very different places in time and thus related to different cultural orders. Both modern musicians of the Middle East and their scholars anticipate changes in music to indicate changes in culture when music is different between geographies and language groups. Yet changes in cultural order also occur across time. Accounting for temporally distinct cultures with specificity across history can answer questions about music history that music alone cannot.

Given the central place of the twelve-maqam system in multiple music histories of the region, it could not have simply evolved into the radif-dastgah tradition within a single, Persian cultural trajectory. Nor could it inevitably evolve into any other modern maqam/makam tradition in relation to a single Turkic or Arabic cultural trajectory. The centrality of cultural stability to modern understandings of music history in the Middle East, whether indigenous or foreign, belies the important implications of musical change and what it reveals about cultural differences between the past and the present. In considering the potential for significant change in music to indicate the existence of different cultural orders in distinct temporal space, the twelve-maqam system is something much more than a mere 
progenitor of the radif-dastgah tradition. The radif-dastgah tradition is also something much more than a mere regurgitation of a perennial culture.

\section{WRITING AND REWRITING PERSIAN MUSIC HISTORY}

In recent years, more critical readings of music history and musicians' historical narratives in areas surrounding Iran have provided a basis to distinguish between past and present musical epistemologies. For instance, Jonathan Shannon distinguishes the contemporary nostalgia of Middle Eastern musicians for medieval alAndalus as a cultural imaginary that lives in contemporary musicians' rhetoric, far away from the realities of medieval Muslim Spain. ${ }^{17}$ In South Asia, research by Katherine Butler and Bonnie Wade has demonstrated that modern agency and cultural synergies created the indigenous tradition of Hindustani music leading up to the nineteenth century. ${ }^{18}$ Beyond these localized deconstructions of historical discourse, the entire discipline of anthropology has also experienced very broad critiques of its culture paradigm via reflexive analysis of the discipline in relation to its subject of culture and indigenous peoples. ${ }^{19}$ Anthropology's internal critique has stemmed in part from the realization that many indigenous traditions that researchers initially identified as quite old were in fact quite new.

In the midst of these changing conceptions of music, history, culture, and tradition, Iran has been largely absent. This is partially due to purely logistical challenges of ethnographic research and music performance. The revolution in 1978-1979 and ensuing upheaval, followed by international sanction, prohibitive travel policies, and heavy government intervention into music regulation, have all provided difficult hurdles for both Iranian musical performance and research. Social and cultural historians have faired somewhat better under the current Iranian government. Research since 1978 on early-twentieth-century Iran has been able to reveal the modern agency involved in the rise of the modern Iranian nation, referencing indigenous interpretations of European intellectual trends such as Orientalism, nationalism, and political activism. ${ }^{20}$

But the Iranian government throughout the twentieth and twenty-first centuries has also done a high degree of enforcement of its own nationalist narratives of Iranian history, making these kinds of alternative interpretations of Persian history for music more difficult. By the 1960s many indigenous musicians and researchers depended on the Pahlavi Ministry of Culture and Ministry of Information for their work, even as the Pahlavi state had been invested in notions of modern Iran as the heir to the great ancient Persian empires for several decades. ${ }^{21}$ In this environment, researchers had the impetus to write within a narrative of Iranian music history that related to the Pahlavi preference to connect Iran to the most ancient interpretation of Persian culture available. ${ }^{22}$ When the revolution in the late twentieth century brought Shi'a Islamic identity to the fore, this placed emphasis on the origins of Iranian identity in the sixteenth century, when Shi'a Islam came to dominate the 
Iranian plateau. Pre-Islamic and even early Islamic history no longer provided the primary framework of Iran's political identity, and thus more historical research of music in Iran now focuses on music from the period from the sixteenth century to the present. The Islamic Republic's influence on music has primarily been directly filtered through its regulation of music performance, which has altered the nature of current music practices in novel ways, even as it claims to maintain some type of native purity. ${ }^{23}$ Yet government ideas about what Iran is, where it come from, and what its ideal cultural essence is change the framework for understandings of music far beyond performance.

More recently, government officials have tried to mix and match various aspects of pre-Islamic and Islamic identity with their specific political interests in modern Middle Eastern affairs. The most visual example of this more recent trend was the ceremonial induction of the ancient Persian ruler Cyrus the Great (600-529 BCE) into the Shi'a government's Basij militia in 2010. ${ }^{24}$ This required the government to get an actor to play the part of the ancient Zoroastrian ruler, upon whom the president placed a kuffiya, the iconic scarf of the mostly Sunni Arab Levant, which the Basij wear both in support of Sunni Palestine and in keeping with the Shi'a organization Hezbollah in Lebanon.

While performing a formal ceremony to symbolically induct a prehistoric Persian king into a modern government militia seems unusual and ostentatious, it demonstrates that the pre-Islamic nationalist narrative that dominated Iranian politics for most of the twentieth century still has power and relevancy. Finding ways to explain or otherwise connect the pre-Islamic nationalist narrative with the more recent history and nationalist discourses of the Islamic Republic is a useful initiative in current Iranian politics. It also demonstrates the futility of taking the modern discourse on Iranian national identity as the historical truth of identity in the Persian-speaking world for all time. Grand spectacles such as this display highly visual juggling of contradictory imagery, highlighting the large amount of agency involved in creating and re-creating a modern national identity. The continuity emphasized in historical discourses surrounding Iran's Persian musicwhether from a musician or a scholar, an Iranian or a foreigner-contradicts the ephemeral construction of unity for a single Iranian culture and history. Modern Iranians write and rewrite their own history, even as the peoples in surrounding nation-states write and rewrite their histories, creating overlap and conflict in historical discourse. Music provides evidence upon which to build multiple subjective interpretations of past realities to explain the ever-changing present moment and prospects for the future. ${ }^{25}$

Ensuring that Iran has a place on the modern political map of the world requires this ongoing negotiation of Iranian identity and objective enforcement of its subjective nature. Despite the perceived historic symmetry between Iran and the Persian language, only about 50 percent of Iranians speak Persian as their first 
language. Iran encompasses a lot of both musical and cultural diversity. Even Persians have music traditions that are unique to one particular region or even one particular city. ${ }^{26}$ Some of its larger language minorities have agitated for national independence over the past century, including Azeris, Baluchis, and Kurds, who all have their own contiguous language regions that defy Iran's borders as well as those of surrounding nations. Within Iran itself, there are multiple possibilities for national divisions that modern Iran has had to confront.

The fall of the Soviet Union in the 1990s and the subsequent independence of Persian- and Turkic-speaking peoples of Central Asia have created even more challenges to Iran's historic Persian façade. While Iran clung to the European label of Persia for most of the twentieth century, the term Persianate emerged as a common term to describe societies that fell outside of Iran's national history as awareness grew of Persian-speaking people in Central and South Asia. When Central Asia emerged as an accessible area for research in the shadow of Iran's Islamic revolution in the 1990s, the use of adjective Persianate soared. Central Asia and South Asia have become prime areas for research on Persianate music while Iran has remained isolated.

All of this demonstrates that Iran is a modern nation-state that must actively work to create and maintain itself as a distinct cultural entity that has political standing in the modern world. Like all nation-states, this requires Iran to engage in ever-changing narratives that justify its historical existence in the midst of changing circumstances and other national possibilities. Iran's national identity is negotiated, renegotiated, and enforced in relation to other nations, who are also negotiating and renegotiating their national identities.

Music has a role to play in such negotiations. Thus, one old song in the radif tradition highlights the negotiation of Iran vis-à-vis Azerbaijan in the early twentieth century, describing Azerbaijan as “Iran's key, Iran's hope, Iran's martyr” while singing against Azerbaijan's Turkic identity by telling it to "avoid the Turks and the Turkish." ${ }^{27}$ More recently, Iran formally turned to the West for musical affirmation of its cultural strength. In 2009, UNESCO approved Iran's application to have the radif inscribed on its "Representative List of the Intangible Cultural Heritage of Humanity." Here the international community officially recognized the radif as a key aspect of Iranian music that "reflects the cultural and national identity of the Iranian people." ${ }^{28}$ These are musical actions taken in an ongoing negotiation of national culture. Iran made its application for the radif to be added to this list a year after UNESCO started it. In its first year, UNESCO added multiple music traditions from Iran's neighbors, including the Azeri Mugham, Uzbek and Tadjik Shahmaqom, and Uyghur Maqam. With nations all around it receiving cultural validation from UNESCO through music, Iran could not afford to be left out. Indeed, Iran is very concerned about its standing in its surrounding region. It is currently very focused on the countries around it and what they can do to com- 
promise Iran's position, including their ability to present affronts to its political interests and cultural identity.

\section{PERSIAN MUSIC IN CULTURAL HISTORY:}

\section{A NEW APPROACH}

While people studying musical practices in areas of the world with little physical documentation of music history may be able to embrace the idea of history as a pure exercise in mythology for the present, it creates a teleological quandary for areas like the Middle East where historical documentation of musical ideas and practice goes back centuries. In meeting Iranian musicians in the twenty-first century and directly experiencing their music and their understanding of their culture, I wanted my research to honor their perspectives, including their interpretations of music history. The feeling of obligation to the present I experienced was immediate and visceral.

This presents a predicament for considering the meaning of the musical past. I can read about the musical past, but I cannot directly observe or hear a reality from centuries in the past. I can ponder how those musicians existed in the past playing different music under very different circumstances, but their reality cannot live with me the way current Iranian music culture can. For this reason, direct experiences with a present musical reality weigh heavily on attempts to understand documentation of the musical past, no matter how many centuries or millennia removed music history is. It is possible to do complex analysis to reveal highly distinct music systems of the past in detail, and yet there is a tendency to construct the significance of music culture past in relation to a designated music culture present, no matter how musically and culturally distinct the past maybe. In considering a new approach to Persian music's historiography, moving away from such telescopic interpretations of the past provides an opportunity to locate the more specific meanings of music at different points in time. This greater specificity of meaning can reveal a more active and arguably more significant role for music and musicians in the societies of the Persian-speaking world, past and present.

In considering how to write historiography that more equally accounts for the possibility of distinctions in musical and cultural order marking differing epochs, I kept reading the historical writings in Persian considered by both musicians and scholars to be the physical and intellectual evidence of Iran's great music history, seeking points of analysis that could provide insight into the musical past on its own terms, with no predetermined narrative direction for culture or identity beyond what documentation could support. I focused my research on the catalog of Persian music treatises compiled by the Iranian musicologist Mohammad Taghi Massoudieh in the late twentieth century, Manuscrits persans concernant la musique. ${ }^{29}$ Besides being an extensive catalog of Persian musical writings in print, I found that this catalog had a certain symbolic significance, acting as a metaphori- 
cal bible of Persian music that documented its historic tales and origins over centuries. Massoudieh was a very influential scholar in late-twentieth-century Iranian musicology and his cataloging of Persian manuscripts validated modern belief in Persian music's unity and antiquity and modern Iran's ownership over this Persian musical legacy. I was also able to analyze writings Massoudieh did not document, but his cataloging of manuscripts remained the center of my research. The types of manuscripts he documented had been used to tell a specific story about Iran's history. I wanted to reanalyze this documentation without the assumptions of Iranian national history.

I quickly discovered that Oriental musicology's influence over indigenous musical thought and the diffuse history of Persian-speaking peoples in Asia reflected the geography of the historical documentation in this catalog and the general trajectory of historical studies of Iranian music history overall. The documentation of Iran's music history cataloged by Massoudieh was all over the Eurasian continent, which held much of it in archives and libraries all over Europe, South Asia, and Central Asia. Researching the catalog required me to travel to Iran, and the United Kingdom, Germany, and France, while requesting documents from archives in the Netherlands, Uzbekistan, Russia, Pakistan, and India. Sometimes I could get Persian music treatises from institutions I could not visit through normal requests to the constituent institutions. Sometimes I shared documents I had access to with Iranian musicologists who needed them, and in turn they shared documentation they had obtained. All this movement belied notions of armchair scholarship. Not even Iranian musicians themselves had full access to Persian music history. They would have to travel far and wide to see it.

I started my research reading texts that other scholars had written about, but also texts no one had written about, and large sections of text that scholars omitted from analysis due to their inability to illuminate practice or their redundancy of discourse. Redundancy of discourse, even purely theoretical concepts, struck me as too important of a phenomenon to ignore. Modern studies of historical music texts from the Middle East have tended to follow medieval European classification of discourse between the purely speculative (musica speculativa or 'ilm) and the practical (musica practica or 'amal), leaving the latter to either admire or ignore and the former to explain what really happened. ${ }^{30}$ But reading all statements and locating consistent patterns of musical discourse across such categorization can reveal and map music's relationship with the cultural order: stable constructs of human belief and meaning and what music contributed to those constructs within a particular space and temporality, in relation to both praxis and possibilities of praxis.

Within this general framework, I saw the need to reread much of what had already been read and I deal with the documentation already recognized as central to Iran's Persian music history. Restricting the analysis of music within the set labels such as "Persian history" or "Iranian culture" put significant limits on 
the types of information that could be valued in these writings and narrowed the possibilities for how they could be analyzed. But in taking music as a key indicator that could define cultural and temporal space, new readings of these texts are possible.

Analyzing musical thought's relationship to the stability and change of the cultural order creates a cultural history of music in the true sense of cultural history: the study of how specific musical knowledge and practice can be aligned with nonmusical knowledge and practice in the broader context of cultural production. The goal of such a cultural history is to identify the specific realities that made different parameters for music-making possible at different points in time. In this approach to historiography, parameters of music culture relate to the successive temporal alignments between discourses within a field (in this case, music) and the discourses of other fields that make up its surrounding context. Within this framework, music is part of an active realm of cultural production that can reveal significant changes in cultural dynamics. More significantly, music analyzed as cultural production in this framework can reveal the dynamics of changing local histories, as well as connections between local history and the broader dynamics of world history.

On its face, this kind of study borrows much from Foucauldian archeology. ${ }^{31}$ In such a study, the purpose of discourse analysis would be to locate a broad conceptual basis for a set of musical possibilities within the cultural order, looking for moments of one discourse's extinction in relation to another, in order to locate successive change in music and culture, rather than a single, evolving cumulative change..$^{32}$ Yet some of the strongest epistemological breaks in the history of Persian-speaking people are not accompanied by wholesale cultural or musical extinction, highlighting points made about the relationship between historical events and the contrasting stability of cultural order in historical anthropology. Thus, Marshall Sahlins insists that the past does not have to be victimized by the present in the sense that it can be analyzed to locate its own unique cultural order. He further suggests, beyond Foucault, that the goal of modern historiography is "understanding people's cultural constructions of events, not of determining 'facts' in the physicalist sense of objective happenings." ${ }_{33}$

In the analysis of historical documentation from this perspective, radical transformations of culture occur in relation to exogenous events and world history, yet the standing cultural order will have input into the process of adaptation and reinterpretation in the establishment of a new order. Indigenous peoples of the Middle East do not simply lose their cultural orders in the midst of invasions, migrations, and colonizations, nor do they maintain the cultural order and render historical events and the causations of world history meaningless to local cultural perspective. Rather, the cultural order becomes a key aspect of how societies adapt to events and establish new cultural order via idiosyncratic responses to the event, not just contact with external forces. In this context, the idea of musical 
tradition is less one of an enduring monument to a single cultural existence and more akin to Marshall Sahlins's definition of tradition as a culturally specific form of change. ${ }^{34}$ Humanity's local musical abilities and knowledge come into play as adaptive responses to changing life circumstances tied to an ever-changing world.

In writing a cultural history of Persian music in this way, Nettl's suggestion of the radif-dastgah tradition emerging from the dual historical events of rising Western cultural hegemony and rising sentiments of nationalism takes on a very different meaning that warrants investigation, with deeper consideration of the relationship between music, cultural order, and historical events. On one hand, social scientists no longer take nationalism for granted as a purely organic pride in a naturally perennial culture of a nation. It is almost a truism to say that nationstates are actively constructed in the modern era, with grand historical narratives built upon purloined historical data. This is the source of modern Iran's ability to give different and even contradictory conceptions of national identity, without ever questioning the legitimacy of Iran's perennial nature. This metaphorical stealing of history is part of the adaptation process: an aspect of older, localized cultural order being actively repurposed in adaptation to modernity, in support of the modern nation.

The specific circumstances encompassing the historical event of modernity's transmutation facilitate a heterogeneous synergy between various aspects of indigenous cultural order, external forces, and the localized contingencies of the event itself. In this context, the modern radif-dastgah tradition is not required to be either a replica or an abandonment of indigenous music culture, nor does it have to be a compromise position between Persian and Western culture. It can be a culturally moded change in music's practice and conception that addresses unique cultural adaptation to the modern world in a particular place. It is not limited to being a static symbol of Iran's national culture: it can be an active producer of Iranian culture that makes the nation of Iran possible, in part by voicing a narrative for modern Iran using new interpretations of indigenous musical expression.

The radif-dastgah tradition's unique historical moment highlights its distinction from the twelve-maqam system. No one writing about, thinking about, or performing within the twelve-maqam system in the fifteenth century had a crystal ball to tell them of the historical events from which the radif-dastgah tradition emerged four centuries later. Though the modern music culture of the radif-dastgah tradition requires the history of the twelve-maqam system to adapt to Iran's modern cultural order, the twelve-maqam system related to a different cultural order, which emerged in the adaptation to very different historical events in the Persian-speaking world: the rise of Islam via Arabic-speaking peoples from the West, and the Mongol Invasion accompanied by Turkic migrations from the East. It is here, in the midst of cosmopolitan, polyglot Islamic empires across Central and West Asia, that the twelve-maqam system became a highly valued model of music's conception and performance practice. 
To consider historical documentation of music in the Persian-speaking world in relation to these contrasting historical events, I identified three categories of musical discourse found across Persian writings about music, from the thirteenth century into the 1940s, which demonstrate the contrasts between the cultural order of the twelve-maqam system and the radif-dastgah tradition. Discourse on the meaning of technical aspects of music's structure and execution directly addresses what made each music system possible and valuable within its constituent historical context. Discourse on the moral parameters of musical practices further extrapolates contrasting moral dilemmas in the execution and conception of musical expression for each constituent music system. Finally, song texts allow musical expression to fully enunciate contrasting priorities of each system's cultural context.

On the basis of these three categories of discourse in relation to two distinct music systems, I have organized my analysis into two parts: part 1 for the twelvemaqam system from the thirteenth to the eighteenth century, and part 2 for the radif-dastgah tradition from the nineteenth century to the 1940s. Chapter 2 is an introduction to part 1, providing a more detailed background and history of the twelve-maqam system and its intellectual practitioners within the Persianate Islamic empires established by Mongol and Turkic rulers. Chapter 3 examines technical discourse on the twelve-maqam system, along with its metaphysical and cosmological underpinnings. Chapter 4 examines the discourses of morality surrounding the practice of listening for divine connection in the context of Islamic mysticism. These discourses run concurrent with the twelve-maqam system, sometimes in the same texts, reflecting on the benefits and perils of mystical practices that used listening to musical expression as a method of direct connection with God. Chapter 5 completes part 1 with an analysis of song text collections from the Timurid courts (1370-1501 CE) and the Safavid courts (1501-1722 CE). These texts highlight the centrality of imperial principles in musical expression, while also demonstrating musical adaptation to the changing politics of empire over time.

Chapter 6 is an introduction to part 2 that provides a more detailed background and history on the radif-dastgah tradition and the historical context of its intellectual practitioners within the fall of the cosmopolitan model of empire and the rise of the nation of Iran. Chapter 7 examines technical discourse on the radifdastgah tradition, focusing on how its structure related to developing national discourses in the descriptions and theoretical models of the tradition described by Forsat al-Dowleh Shirazi (1855-1920), Mehdi Qoli Hedayat (1864-1955), and Ali Naqi Vaziri (1887-1980). Chapter 8 examines the changing morality of music in this newly nationalized culture, considering the moral issues of national music discussed from different perspectives by Vaziri and the singer-poet Aref Qazvini (1882-1934). Chapter 9 examines the nationalist choices that create much of the original structure for radif-dastgah performance, as well as the modern nationalist 
discourses of tasnif (tașnif) — the metered song compositions commonly inserted into radif-dastgah performances.

In chapter 10, I conclude by reflecting on the significant contingencies that put Iran's musical modernity on a unique path, which was further shaped and reshaped by different readings of what the nation of Iran needed from its music in order to survive and thrive. I consider the larger picture of the contrasts between the radif-dastgah tradition and the twelve-maqam system, and return to the question of methodology in music historiography and how placing cultural production at the center of music history sheds light on music's larger role in both local and world history. 